\title{
Developing a User Typology for the Analysis of Participation in Enterprise Collaboration Systems
}

\author{
Florian Schwade \\ University of Koblenz-Landau \\ Institute for Information Systems Research \\ Faculty of Computer Science \\ Germany \\ fschwade@uni-koblenz.de
}

\author{
Petra Schubert \\ University of Koblenz-Landau \\ Institute for Information Systems Research \\ Faculty of Computer Science \\ Germany \\ petra.schubert@uni-koblenz.de
}

\begin{abstract}
In this paper, we propose a user typology for Enterprise Collaboration Systems (ECS). We draw on and extend findings from previous research in the area of CSCW and Social Collaboration Analytics. The proposed typology includes: (1) a definition of user types, (2) dimensions of ECS use and (3) a classification of action (event) types. The typology contains the following user types: creator, contributor, lurker, inactive and non-user. These types are characterized by differences in the following dimensions: type of use, frequency of use, variety of use, choice of content type and platform preferences. The definition of user types along these dimensions facilitates the implementation of database queries (scripts) for Social Collaboration Analytics (SCA), with the aim of determining the distribution of types of users in an Enterprise Collaboration System. We present selected results of such SCA for an integrated collaboration platform and discuss the findings. We successfully demonstrate that our classification of user types allows us to draw conclusions on (1) the form and degree of participation of users in the ECS and, derived from that, (2) the likely purpose of the examined communities.
\end{abstract}

\section{Introduction, Terminology and Re- search Approach}

The last 10 years have seen a remarkable increase in the number of companies that provide integrated Enterprise Collaboration Systems (ECS) to support employee collaboration [40]. ECS are a means to electronically support different areas of workplace collaboration [31] such as information and content sharing, communication, cooperation and coordination as described in the $8 \mathrm{C}$ Model for Enterprise Information Management [39]. The latest types of ECS are "socially-enabled", providing social media functionality such as recommend, like, follow, tag or rate, which are used on content items such as social profiles, microblogs, wiki pages, blog posts, files or tasks. ECS combine various social media features and social content items with classical groupware functionality (e.g. e-mail and group calendar). Consequently, companies introduce ECS with the aim of improving information sharing and employee collaboration. However, studies have shown that companies struggle to actually realize the objectives of ECS introduction projects [40] and that current analytics tools do not provide collaboration professionals with the information required to purposefully manage their platforms and communities [33]. This prevents collaboration professionals from measuring and tracking the adoption progress of their users in a structured way. Consequently, there is a lack of information on how ECS are actually used in the organization.

Social Collaboration Analytics (SCA) is a term used to describe the systematic approach for measuring and displaying collaboration activities in an ECS [32]. A recent literature review [34] identified seven key application areas for SCA: (1) measurement of system usage, (2) analysis of communities, (3) identification of types of users, (4) identification of expertise, (5) identification of usage patterns, (6) analysis of networks and (7) measuring organizational and cultural impacts of ECS on the organization and vice versa.

An online survey [33] among collaboration practitioners showed that - with the exception of the first area "(1) measurement of system usage" - these types of analyses are not yet widely conducted in practice. The authors identify a lack of functionality in the analytics tools as one of the main reasons. At the same time, the study [33] reports on the findings from workshops with a group of practitioners that revealed $a$ strong interest in analyzing participation and activity of users in ECS.

In this paper, we place attention on the third area: (3) identification of types of users in the specific appli- 
cation domain of ECS. We propose a typology of user types (and their respective characteristics), which assist us with the practical implementation of SCA in order to measure participation in ECS. An analysis of the literature on SCA identified an inconsistent use of the terms "active users" and "inactive users". Some authors define active users as "users with one viewing activity in the past 30 days" [26], others use the same definition for inactive users [30]. Performing SCA, however, requires precision and clarity on these terms in order to measure and identify them in the content and usage data of an ECS.

This paper seeks to answer the following research questions:

1. Which user types can be identified in ECS and how are they characterized?

2. Which dimensions are suitable to describe ECS usage?

3. What information can be gained from analyzing user types in an ECS?

The main contribution of this paper is the ECS user typology. The remainder of this paper is structured as follows: Section 2 describes the research design of this work. This is followed by a literature review and discussion of user types in online platforms. Based on this discussion, we develop dimensions for ECS use, collaborative actions in ECS and the ECS user typology. We conclude with an exemplary analysis of user types from an existing (integrated) collaboration platform (UniConnect) and a discussion of limitations and future work. Thus, the second contribution of this paper is a successful application of the proposed user typology in a study using data from a large-scale ECS with more than 3500 users.

\section{Research Design}

This work is part of a publicly funded longitudinal university-industry collaboration involving 29 earlyadopter ECS user companies. The participants have agreed to provide information on their ECS adoption projects and their actual system data. A group of University researchers moderates the research initiative. The participating practitioners have different educational backgrounds, e.g. in information technology, information and knowledge management, internal communications or business development.
Figure 1 shows the research design for the development of the user typology. Over the last three years, the group conducted eight physical workshops covering various aspects of ECS such as implementation and change management, benefits measurement, Social Collaboration Analytics or document management to foster a mutual exchange of ideas and discuss possible solutions to problems. In these workshops, the researchers present their findings, which are discussed and reviewed by the participants. This enables a constant cycle of evaluation [41].

In the course of the workshops, the researchers identified key issues for SCA and described the status quo of SCA in practice. These established the problem awareness. The findings from this empirical part of the project are continuously complemented by literature reviews; one of them being focused on user types. Based on the literature, we (1) derived a user typology for ECS, (2) identified dimensions for ECS use and (3) classified collaborative actions in ECS. These results were then evaluated and refined in a research workshop.

In the last phase (development and evaluation), we implemented and tested the ECS user typology in the form of SQL statements, which allowed us to analyze the distribution of user types in a live ECS. The interpretation and discussion of results completes the evaluation of the user typology following the DSR approach [37].

\section{Literature Review: User Types}

Two classifications of user types are frequently referenced in the literature: The unified model of MediaUser Typology (MUT) by Brandtzæg [3] (for online media users) and the proposed user roles by Muller et al. [23] (identified on a file sharing platform).

These two approaches served as the starting point for the development of the typology of users proposed in this paper. A critical analysis of the MUT by Brandtzæg [3] and the user roles by Muller et al. [23] served as the foundation for a snowball search for literature including forward and backward search.

The MUT defines eight types of users based on four dimensions for media platform usage. Non-users are the users who do not use media services at all. Media use of sporadics is characterized by low frequency and variety of use. Sporadics use a media platform

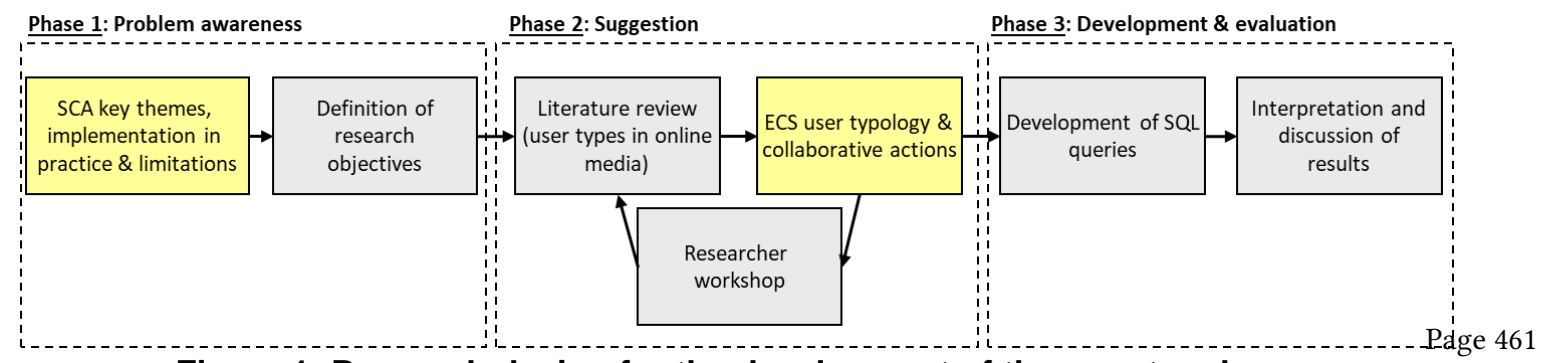

Figure 1: Research design for the development of the user typology 
every now and then. According to the MUT, media usage of lurkers is characterized by a medium frequency of use and a low variety of use. Following Brandtzæg [3], lurkers only consume content. As there is an extensive discussion on lurkers in the academic literature, section 3.3 discusses lurkers and their characteristics in more detail. Entertainment users or socializers use a media platform for entertainment and connecting with other people. In contrast to this, debaters participate in discussions and instrumental users use a media platform as a tool for a special purpose. Finally, Brandtzæg [3] defines advanced users as the users who are most active and use the most features of a media platform.

The MUT is displayed in the form of a pyramid, which, in our opinion, might not be the ideal form to group/classify user types. The most active and most skilled types are at the top and the lowest are on the bottom. This would indicate that lurkers are less active than the user types above them, what we believe is not necessarily the case. Another limitation of the MUT is the inconsistent classification of user types. Non-users and sporadic users are mostly described by the frequency of media use whereas entertainment users and instrumental users are characterized by their typical activities. Finally, the variety of use primarily characterizes advanced users. Putting the focus on different dimensions in the typology leads to an inconsistent classification [2].

The user roles proposed by Muller et al. [23] provided us with a suitable starting point for our own classification. They include the roles: lurkers, contributors and uploaders. Following Muller et al. [23], lurkers "never deliberately add information to the database, but they do engage in traditionally 'non-public' actions". Consequently, lurkers only consume content. In contrast to this, contributors "do not upload files, but they do create metadata about files through actions such as commenting, sharing to specific other users, adding files to named collections of files, and adding tags to files such as downloading files". Thus, contributors rather create metadata about files. Finally, uploaders "create files in the service through upload operations" and thus create primary content. Muller et al. [23] proposed these roles in the context of a file sharing system. As file sharing systems lack most of the social features that are available in socially-enabled ECS, we saw the need to extend the user roles and their definitions. Especially concerning the uploader role, modern ECS provide more possibilities for creating new content than just uploading files. The user roles suggested by Muller et al. [23] were "self-selected" and there is no indication that they are theoretically or empirically grounded. In order to enrich the user typology we conducted a snowball search in the literature that resulted in 41 papers. We identified three main themes: (1) dimensions for platform use, (2) collaborative actions and (3) user typologies. These three themes are presented and discussed in the following sections.

\subsection{Dimensions for ECS use}

We address the call to action by Blank and Groselj who argue that "before engaging with the data, the nature of [...] use has to be theorized along meaningful dimensions" [2]. In our literature review, we paid special attention to dimensions of platform usage and synthesized the discussed dimensions into a typology suitable for ECS platform use. In the following, we present a summary and discussion of dimensions for ECS use.

The dimension frequency of use is the most considered dimension for platform use in the literature. This dimension describes how often and how long users use a platform. In contrast, the dimension types of use is rarely explicitly addressed [2, 8, 17]. Blank and Groselj [2] criticize the way that most authors merge the dimension types of use into the dimension frequency of use. These dimensions are, in fact, mutually exclusive as users can show a different behavior regarding these two dimensions. As types of use refers to what users do on a platform and frequency of use describes how often a platform is used, we incorporate this clear distinction.

Table 1: Dimensions for ECS use

\begin{tabular}{|c|c|c|}
\hline Dimension & Definition & Ref. \\
\hline Types of use & $\begin{array}{l}\text { What users do on a } \\
\text { platform }\end{array}$ & {$[2,8,17]$} \\
\hline $\begin{array}{l}\text { Frequency of } \\
\text { use }\end{array}$ & $\begin{array}{l}\text { How often users } \\
\text { use a platform }\end{array}$ & $\begin{array}{l}{[2,3,4,7,8,} \\
16,21,35]\end{array}$ \\
\hline Variety of use & $\begin{array}{l}\text { Variety of purposes } \\
\text { for platform use }\end{array}$ & $\begin{array}{l}{[2,3,4,21,} \\
35]\end{array}$ \\
\hline $\begin{array}{l}\text { Choice of con- } \\
\text { tent type }\end{array}$ & $\begin{array}{l}\text { Chosen content } \\
\text { type }\end{array}$ & {$[3,4]$} \\
\hline $\begin{array}{l}\text { Platform pref- } \\
\text { erences }\end{array}$ & Preferred platform & {$[3,4]$} \\
\hline
\end{tabular}

The dimension variety of use indirectly results from types of use as this dimension describes the variety of different purposes for platform use [2, 3, 4, 21, 35]. Finally, the dimension "choice of content type" describes the type of content users prefer and the dimension platform preference describes the platform, which is preferred by users [3, 4]. In the context of our own research, the choice of content type refers to the different content types such as blogs, wikis, files or forums. Table 1 shows the dimensions of ECS use that we identified in the literature and that we incorporated in our new typology of user types. The table reveals that there is currently no study that addresses all of these 
dimensions. By including all five dimensions identified in the comprehensive literature analysis and by gaining valuable insights from experienced collaboration professionals (in interactive workshops), we provide a classification of user types that is relevant for practice and thoroughly grounded in theory, as called for by Blank and Groselj [2].

\subsection{Collaborative actions in ECS}

As outlined in the previous section, the dimension types of use is essential for distinguishing user types since this dimension describes what users actually do on a platform. Thus, a detailed analysis and classification of user actions in ECS is required. The academic literature suggests few classifications for user actions in ECS. The revised framework for Identification of Requirements for Enterprise Social Software (IRESS) by Schubert and Glitsch [11] makes use of the collaborative usage patterns (CUP) matrix suggested by Richter et al. [28]. Richter et al. [28] propose seven collaborative actions (1) search, (2) edit, (3) rate, (4) label, (5) clarify, (6) share and (7) notify.

Table 2: Collaborative actions in ECS

\begin{tabular}{|l|l|}
\hline Action type & Description \\
\hline Create & $\begin{array}{l}\text { Creation of a new core element of a } \\
\text { SBD }\end{array}$ \\
\hline Alert & Notify about existing content \\
\hline Consume & Consume content \\
\hline Network & Network relations with other users \\
\hline $\begin{array}{l}\text { Modify } \\
\text { change/add) }\end{array}$ & Modify existing content \\
\hline Discuss & Discussing content or topics \\
\hline Task mgmt & Working with tasks \\
\hline Delete & Delete content \\
\hline
\end{tabular}

Whilst these collaborative actions provide a starting point for classifying actions in ECS, we identify several inconsistencies. Firstly, the collaborative actions do not consider activities for consuming content and networking activities. Considering the constant discussion on lurkers and their implications and value for collaboration systems, consuming activities are an important action type that is missing in the CUP matrix. Secondly, with regard to creating and sharing content, there is a further inconsistency in the collaborative actions. The action notify is defined as "notify others about relevant content, which already exists" [28] whereas the action share is defined as "provide content in order to make it available to others" [28]. When looking at how this terminology is used in Social Software, these labels might be misleading, e.g. "share" might not imply providing (and thus adding new) content but just giv- ing access rights to or simply notifying others about existing content.

Other studies base their analysis on the common create, read, update, delete (CRUD) operations. CRUD describes the common data operations. However, in the context of SCA, additional meaning is required and the distinction between these four operations is not sufficient. Consequently, we propose a new preliminary classification of collaborative action types for ECS (Table 2).

Considering the nature of content in ECS, the concept of compound Social Business Documents provides a lens on collaborative actions. SBD typically consist of multiple components. In the case of a wiki page, the core element of an SBD is the wiki page with the content itself. Several components can be added to this core element by adding tags, versions or comments [14]. We believe that the characteristics of SBD should also be reflected in the classification of collaborative actions. The action type (1) create refers to user actions, which result in the creation of a new core element of an SBD. Examples are new posts or pages, uploading files or creating status updates (microblogs/tweets). In contrast to this, the collaborative actions modify and discuss do not create or alter the core element but add new components to the SBD instead.

The collaborative action (2) modify refers to modifying existing content. We distinguish between modify (add) and modify (change). Actions in modify (change) alter either the core element of an SBD or one of its components by revising, editing or updating them. In contrast, actions in modify ( $a d d$ ) add new components to a SBD by commenting, rating, tagging or liking them.

Similarly, when (3) discussing content by commenting, additional components are added to an SBD by posting comments, responses or marking discussions as solved.

As previously argued, a distinction between creating new and sharing existing content is needed. Consequently, the collaborative action (4) alert describes actions for notifying other users about existing content for example by placing notifications.

The collaborative actions consume and network are closely related. (5) Consume refers to consuming content by reading posts or downloading files. (6) Network actions create relations with other users by following them or adding them to the network by sending contact requests. In integrated ECS, retrieve and network actions are the foundation for the generation of the individual activity stream. The activity stream is generated based on subscriptions to content and relations to users.

A special feature of groupware and ECS is (7) task management. To date, task activities have not yet been 
discussed in the context of user types; an open issue that we are addressing in our typology.

Finally, the (8) delete action refers to deleting existing content.

Concluding, the action types create, consume, and modify (add/change) - like the CRUD operations follow the core phases of the information life cycle whereas alert, network, discuss and task management represent key collaboration features in ECS. Thus, our classification of collaborative actions is based on the information life cycle and on the concept of compound SBDs [14].

We strongly argue that a clear distinction of these collaborative actions is important for achieving precise measuring results. Previous studies investigate user types on the level of download, share, collect, annotate, tag and upload. The real challenge for the actual analysis in the collaboration system is the preceding assignment of events types (stored in the event $\log$ ) to the terms defined in our typology. For example, the Enterprise Collaboration System "IBM Connections" stores the "adding of a network contact" as a "create event" in its event log. In order to resolve this ambiguity it is necessary to set up a "mapping table" between the terminology used by the collaboration software (in the event $\log$ ) and the terminology in our typology. In many cases, the combination of the content type (in this example "a network contact") and the atomic action (in this case "create") determines which category the action has to be assigned to.

\subsection{Developing the ECS user typology}

From the literature, 102 definitions for various user types were identified. A closer analysis of the literature revealed that the discussion concerning user types in the academic literature focus particularly on the role and characteristics of lurkers. The level of discussion on other user types is comparably low.

We also observed that most of the proposed user typologies were developed as general online media or ICT typologies, which included user types such as attention attractors (enjoying sharing private life and achievements with others) [20], netizens (incorporated the Internet in their daily life) [18], broad frequent users (use a service for more than three purposes) [35] and others. Such user types are not suitable in the context of collaboration systems. Consequently, this reduced the number of useful definitions to 51 . The literature review revealed two publications, which contribute user typologies specifically for collaboration systems. The typology by Muller et al. [23] proposes the user types lurkers, contributors and uploaders whereas the typology by Bezzubtseva and Ignatov [1] consists of the user types inactives, idles, critics, debaters and celebrities. The user types by Bezzubtseva and Ignatov [1] contain the same limitations as previously argued for the MUT. While the types inactives and idles focus on frequency of use, critics and debaters focus on types of use. Thus, the proposed user typology by Bezzubtseva and Ignatov [1] is not suitable for our analysis of user types in ECS. We identified a number of user typologies that contained a similar (unfortunate) mixture of usage dimensions [7, 8, 15, 17, 18, 35].

An in-depth analysis of the remaining 51 user types and their definitions revealed similarities with the user typology proposed by Muller et al. [23]. Considering the limitations of this user typology, we used the proposed typology by Muller et al. [23] to categorize the user types identified in our literature review using a card sorting approach. This categorization resulted in a user typology including the user types lurkers, contributors and creators. Additionally, we identified the three additional user types inactives, non-users and users without an account. Table 3 provides an overview on the final ECS user typology including the definitions and their types of use.

\section{Table 3: ECS user typology}

\begin{tabular}{|l|l|}
\hline Type & Definition \\
\hline Creator & $\begin{array}{l}\text { A creator creates or uploads new and } \\
\text { original content in a workspace. }\end{array}$ \\
\hline Contributor & $\begin{array}{l}\text { A contributor is a user who contributes } \\
\text { to existing content, for example by } \\
\text { editing, commenting, tagging or rec- } \\
\text { ommending content. However, a con- } \\
\text { tributor does not create or upload new } \\
\text { content. }\end{array}$ \\
\hline Lurker & $\begin{array}{l}\text { A lurker is a user who primarily en- } \\
\text { gages in consuming activities. Usually, } \\
\text { lurkers do not contribute information } \\
\text { or knowledge to a workspace. Howev- } \\
\text { er, lurkers can engage in task manage- } \\
\text { ment and building a network. }\end{array}$ \\
\hline Inactives & $\begin{array}{l}\text { An inactive user is a user who used the } \\
\text { platform in the past but has not used } \\
\text { the platform in the last 12 months }\end{array}$ \\
\hline Non-users & $\begin{array}{l}\text { Everyone who has an account but who } \\
\text { has never logged in. }\end{array}$ \\
\hline $\begin{array}{l}\text { Users } \\
\text { without } \\
\text { account }\end{array}$ & $\begin{array}{l}\text { Employees of an organization who do } \\
\text { not have an account for the platform. }\end{array}$ \\
\hline
\end{tabular}

We argue that there are multiple perspectives from which users can be analyzed in ECS. Whilst user roles [38] classify users according to how they use a system, the user typology provides insights into the degree of participation. To accommodate the limitations concerning the mixture of dimensions, the definitions of the user types include the ECS usage dimensions types of 
use, frequency of use and variety of use. Section 5 elaborates on the remaining usage dimensions choice of content type and platform preferences. The following sections present and discuss the definitions of the types of users.

As identified previously, lurkers are frequently discussed in the academic literature. In total, we identified 22 different definitions for a lurker. Due to space limitations, Table $4 \mathrm{ff}$. only provide an excerpt of the complete list of definitions.

Table 4: Lurkers (excerpt, 9/102)

\begin{tabular}{|l|l|}
\hline Definitions & Ref. \\
\hline Lurker: Persistent but silent audience & {$[27]$} \\
\hline $\begin{array}{l}\text { Lurker: Posted once in the last three } \\
\text { months }\end{array}$ & {$[25]$} \\
\hline $\begin{array}{l}\text { Lurker: Members who do not post more } \\
\text { than one message in a 6 week period }\end{array}$ & {$[13]$} \\
\hline $\begin{array}{l}\text { Lurker: Actively consumes media yet does } \\
\text { not contribute knowledge }\end{array}$ & {$[5]$} \\
\hline $\begin{array}{l}\text { Lurkers: Download files but do not deliber- } \\
\text { ately add information }\end{array}$ & {$[23]$} \\
\hline $\begin{array}{l}\text { Lurker: Community member who has made } \\
\text { zero visible contributions to the community }\end{array}$ & {$[22]$} \\
\hline Lurker: Consuming rather than interacting & {$[3]$} \\
\hline Inactive users: Do not contribute & {$[30]$} \\
\hline $\begin{array}{l}\text { Active users: One viewing activity in the } \\
\text { past 30 days }\end{array}$ & {$[26]$} \\
\hline \multicolumn{2}{|l}{ While most of the definitions state that lurkers con- } \\
\hline
\end{tabular}

While most of the definitions state that lurkers consume resources and do not contribute any information, some authors argue that lurkers might occasionally provide contributions. Several different thresholds for lurkers posting content are mentioned in the literature: not posted recently [25], members who made no contribution to the community during a three month period [25], users who post three or fewer messages from the beginning [10] or users who posted messages only once in a long while [12]

These definitions and their discussion indicate that while lurkers are mostly consuming, they might occasionally provide contributions $[6,36]$. However, the thresholds mentioned in the academic literature are fuzzy (e.g. "recently", "once in a long time") and there is disagreement about the level and frequency of contributions [12, 25]. For our preliminary analysis on user types, we define that a lurker provided less than 10 contributions in the previous 12 months. Section 4 contains further discussion on this threshold level including a proposal to adapt this threshold to the context of analysis. The literature frequently mentions that lurkers are mostly consuming information and engage in 'invisible' actions, however we found no in-depth discussion about the activities that lurkers can potentially engage in. As previously argued, this discussion is necessary, especially since the nature of ECS signifi- cantly differs from general media or ICT use. We follow the main definitions from the literature, which argue that lurkers primarily consume content. Since ECS are designed to support joint work, lurkers can also engage in task-related activities. The creation and completion of tasks does not add new intellectual information to a workspace. Additionally, lurkers can build a network in an ECS, which allows them to access, and retrieve relevant information. This results in a low variety of use. Considering the frequency of use, we address another misconception in the literature. Lurkers are typically defined as the least active user type having the lowest frequency of use [3]. We argue that, to the contrary, a lurker might use an ECS more frequently than a contributor or creator. Consequently, we define lurkers as follows:

- Definition: A lurker is a user who primarily engages in consuming activities. Usually, lurkers do not contribute information or knowledge to a workspace. However, lurkers can engage in task management and networking activities.

- Types of use: task management, network, consume

- Frequency of use: less than 10 contributions and 10 creations in last 12 months

- Variety of use: low - high

The academic literature does not clearly distinguish between contributors and creators (c.f. definition originator in Table 5). Considering the nature of SBD consisting of a core element and additional components, we strongly argue that we need to distinguish between users who create new content (creators) and users who contribute to existing content (contributors). Table 5 provides an excerpt from the definitions in the literature for contributor.

Table 5: Contributors (excerpt, 5/102)

\begin{tabular}{|l|l|}
\hline Definitions & Ref. \\
\hline $\begin{array}{l}\text { Annotator: Annotate, add meaning or share } \\
\text { existing publications }\end{array}$ & {$[5]$} \\
\hline Contributor: Contribute content & {$[9]$} \\
\hline $\begin{array}{l}\text { Contributor: Contributors do not upload } \\
\text { new files, but comment and share files }\end{array}$ & {$[23]$} \\
\hline $\begin{array}{l}\text { Participating users: Active engagement in } \\
\text { the form of commenting, rating or editing }\end{array}$ & {$[26]$} \\
\hline Debaters: Comment and evaluate actively & {$[1]$} \\
\hline
\end{tabular}

Considering the frequency of use, we argue that contributors have at least made 10 contributions in the last 12 months. Additionally, contributors can occasionally create new content. Consequently, for the definition of contributors, we propose the following:

- Definition: A contributor is a user who contributes to existing content, for example by editing, commenting, tagging or recommending content. How- 
ever, a contributor does not create or upload new content.

- Types of use: task management, alert, networking, consume, delete, modify (add/change), discuss, consume

- Frequency of use: at least 10 contributions but less than 10 creations in last 12 months

- Variety of use: low - high

Table 6 provides an excerpt of definitions retrieved from the literature for creators.

Table 6: Creators (excerpt, 7/102)

\begin{tabular}{|l|l|}
\hline Definitions & Ref. \\
\hline Creators: Idea generators and creators & {$[1]$} \\
\hline $\begin{array}{l}\text { Poster: Wrote at least two messages during } \\
\text { the study period }\end{array}$ & {$[13]$} \\
\hline $\begin{array}{l}\text { Publisher: Carries out an action resulting in } \\
\text { original content }\end{array}$ & {$[5]$} \\
\hline Poster: Post content to the community & {$[27]$} \\
\hline Uploader: Create files in the service & {$[23]$} \\
\hline $\begin{array}{l}\text { Contributing users: Active creation of con- } \\
\text { tent in the previous 30 days }\end{array}$ & {$[26]$} \\
\hline The angels: Share knowledge & {$[20]$} \\
\hline
\end{tabular}

Creators can engage in all the contributor actions. Following these definitions, we define creators as follows:

- Definition: A creator creates or uploads new and original content in a workspace.

- Types of use: create, task management, alert, networking, consume, delete, modify (add/change), discuss

- Frequency of use: at least 10 creations in last 12 months

- Variety of use: low - high

Considering that ECS use is mostly voluntary, some employees might refrain from ECS use [19]. To accommodate this, we identified three additional types of users: inactives (did not use the platform in the last 12 months), non-users (have an account but have never logged in) and users without an account (do not have an account). The definitions mentioned in the literature are summarized in Table 7 and Table 8.

Table 7: Inactives (excerpt, 3/102)

\begin{tabular}{|l|l|}
\hline Definition & Ref. \\
\hline $\begin{array}{l}\text { Inactive: registered and not provided any } \\
\text { kind of interaction thereafter }\end{array}$ & {$[5]$} \\
\hline $\begin{array}{l}\text { Inactive: Those who do not use the service or } \\
\text { quit the service }\end{array}$ & {$[20]$} \\
\hline Inactive: Those who do absolutely nothing & {$[1]$} \\
\hline
\end{tabular}

Table 8: Non-users (excerpt, 5/102)

\begin{tabular}{|l|l|}
\hline Definition & Ref. \\
\hline Non-users: Not using the platform & {$[13]$} \\
\hline $\begin{array}{l}\text { Non users: lack access to, or ability or inter- } \\
\text { est in using media }\end{array}$ & {$[3]$} \\
\hline Non-users: Not used in past 12 months & {$[35]$} \\
\hline $\begin{array}{l}\text { Non-users: It is important to emphasize the } \\
\text { high share of non-internet users }\end{array}$ & {$[7]$} \\
\hline Non-users: Don't use ICT & {$[15]$} \\
\hline
\end{tabular}

\section{Implementation of the User Typology and Analysis of User Types in an ECS}

The user typology was implemented as SQL scripts to enable the analysis of live data from the ECS UniConnect. UniConnect is a collaboration platform provided for universities with more than 3500 users based on the ECS IBM Connections. The literature discusses some limitations for analyzing user types in ECS. For example, Muller and Ridings mentioned that in some systems reading activities are not recorded which makes it impossible to measure lurking activities [23, 29]. In the case of UniConnect, we have full access to the transactional data containing the complete event $\log$ of UniConnect. This allows a thorough analysis of types of users and their activities in the ECS.

The development of the SQL queries was challenging because in IBM Connections the event log records more than 50 different types of user events. A thorough analysis of the event log revealed that some events are always automatically triggered after a certain other event or they are system tasks. Such events are excluded from the analysis because they do not represent user activity. After a careful analysis of the event log, we grouped (assigned) the events to the collaborative actions. Following this, the SQL statements were developed. In order to address the discussions from the literature, we conducted our analysis of types of users on different levels.

In the first step, we analyzed the distribution of the user types lurkers, contributors and creators on the (1) platform level. Next, we address the dimension (2) choice of content type, by investigating the distribution of types of users for each content type. The literature mentions that users may contribute to specific workspaces but may lurk in other communities. [6, 24, 38]. Thus, we investigated the distribution of these user types on the (3) community level for three different community types: teaching communities, project communities and general information communities. 


\subsection{Platform level and content type}

The analysis of user types on the platform level reveals that $77 \%$ of the users are lurkers, $4.73 \%$ of the users are contributors and $18 \%$ of the users are creators. This is an interesting result as the literature consistently refers to $90 \%$ of users being lurkers, $9 \%$ contributing to content and $1 \%$ creating new content (909-1 rule). Considering the nature of ECS, these results are not unexpected. ECS are part of the digital workplace and thus emphasize joint work. Consequently, the percentage of contributors and creators is higher. The number of creators is higher than the number of contributors because collaboration is focused on creating original content. However, it can be observed that similarly to public social media, the majority of users are lurkers.

In order to gain a deeper understanding on this distribution of user types, we conducted another analysis for content types. The share of user types varies depending on the content type. In Wikis, the share of lurkers is the lowest $(80 \%)$. At the same time, Wikis have a very high share of contributors (11\%) and a comparably high share of creators (almost 9\%). This shows that Wikis are an interactive content type in ECS. Creators share their knowledge by creating new pages and contributors enhance these pages by adding revisions, comments, tags or recommendations.

Table 9: Platform level and content types

\begin{tabular}{|l|l|l|l|l|}
\hline & Lurker & $\begin{array}{l}\text { Contribu- } \\
\text { tor }\end{array}$ & $\begin{array}{l}\text { Crea- } \\
\text { tor }\end{array}$ & Total \\
\hline $\begin{array}{l}\text { Platform } \\
\text { level }\end{array}$ & $\begin{array}{l}76.98 \% \\
(1187)\end{array}$ & $\begin{array}{l}4.73 \% \\
(73)\end{array}$ & $\begin{array}{l}18.29 \% \\
(282)\end{array}$ & 1542 \\
\hline Blogs & $\begin{array}{l}93.81 \% \\
(803)\end{array}$ & $\begin{array}{l}3.86 \% \\
(33)\end{array}$ & $\begin{array}{l}2.34 \% \\
(20)\end{array}$ & 856 \\
\hline Wikis & $\begin{array}{l}80.14 \% \\
(573)\end{array}$ & $\begin{array}{l}11.05 \% \\
(79)\end{array}$ & $\begin{array}{l}8.81 \% \\
(63)\end{array}$ & 715 \\
\hline Forums & $\begin{array}{l}92.09 \% \\
(955)\end{array}$ & $\begin{array}{l}4.53 \% \\
(47)\end{array}$ & $\begin{array}{l}3.38 \% \\
(35)\end{array}$ & 1037 \\
\hline Files & $\begin{array}{l}82.84 \% \\
(1091)\end{array}$ & $\begin{array}{l}1.37 \% \\
(18)\end{array}$ & $\begin{array}{l}15.79 \% \\
(208)\end{array}$ & 1317 \\
\hline $\begin{array}{l}\text { Activi- } \\
\text { ties }\end{array}$ & $\begin{array}{l}86.10 \% \\
(322)\end{array}$ & $\begin{array}{l}10.16 \% \\
(38)\end{array}$ & $\begin{array}{l}3.74 \% \\
(14)\end{array}$ & 374 \\
\hline $\begin{array}{l}\text { Book- } \\
\text { marks }\end{array}$ & $\begin{array}{l}97.31 \% \\
(434)\end{array}$ & $\begin{array}{l}2.47 \% \\
(11)\end{array}$ & $\begin{array}{l}0.22 \% \\
(1)\end{array}$ & 446 \\
\hline $\begin{array}{l}\text { Idea } \\
\text { blogs }\end{array}$ & $\begin{array}{l}88.15 \% \\
(119)\end{array}$ & $\begin{array}{l}11.11 \% \\
(15)\end{array}$ & $\begin{array}{l}0.74 \% \\
(1)\end{array}$ & 135 \\
\hline
\end{tabular}

In contrast to Wikis, the percentage of lurkers in blogs is significantly higher, whilst the number of contributors and creators is significantly lower. This indicates that blogs are a content type that is more often consumed as fewer people create new posts and contribute to them.
The content type files showed the most striking results. Files have by far the highest number of creators at $15 \%$. However, the number of contributors is the lowest (1.37\%) among all content types. Additionally, files are the most frequently used content type on the analyzed platform UniConnect. In contrast to wikis, files are created and there are fewer contributions.

\subsection{Community level}

We performed a plausibility check on the data [37]. The figures were manually evaluated by the authors by examining and cross-checking the content in the selected communities.

Table 10: Results for selected communities

\begin{tabular}{|l|l|l|l|l|}
\hline $\begin{array}{l}\text { Com- } \\
\text { munity: }\end{array}$ & Lurker & $\begin{array}{l}\text { Contribu- } \\
\text { tor }\end{array}$ & $\begin{array}{l}\text { Creat- } \\
\text { or }\end{array}$ & Total \\
\hline Project 1 & $\begin{array}{l}34.25 \% \\
(25)\end{array}$ & $\begin{array}{l}35.62 \% \\
(26)\end{array}$ & $\begin{array}{l}30.14 \% \\
(22)\end{array}$ & 73 \\
\hline Project 2 & $\begin{array}{l}52.00 \% \\
(13)\end{array}$ & $8.00 \%(2)$ & $\begin{array}{l}40.00 \% \\
(10)\end{array}$ & 25 \\
\hline $\begin{array}{l}\text { Teach- } \\
\text { ing 1 }\end{array}$ & $\begin{array}{l}71.25 \% \\
(114)\end{array}$ & $\begin{array}{l}7.50 \% \\
(12)\end{array}$ & $\begin{array}{l}21.25 \% \\
(34)\end{array}$ & 160 \\
\hline $\begin{array}{l}\text { Teach- } \\
\text { ing 2 }\end{array}$ & $\begin{array}{l}76.25 \% \\
(113)\end{array}$ & $3.38 \%(5)$ & $\begin{array}{l}20.27 \% \\
(30)\end{array}$ & 148 \\
\hline $\begin{array}{l}\text { Info ex- } \\
\text { change }\end{array}$ & $\begin{array}{l}96.63 \% \\
(344)\end{array}$ & $1.97 \%(7)$ & $\begin{array}{l}1.40 \% \\
(5)\end{array}$ & 356 \\
\hline
\end{tabular}

On the community level, we modified the threshold for creations and contributions to 3 as the analysis on the community level is more focused.

The results for the analysis at the community level show that the distribution of user types depends on the type of community. In project communities, the share of lurkers is lower whereas the share of contributors and creators is higher compared to other community types. In project community 1 , there is an almost equal share of user types. This community is used for the coordination of our university-industry collaboration project. During physical workshops, participants use the community to share insights and impressions. After the workshops, the project team uses the community to document findings and to discuss topics of interests. We believe that the activity in this community is exceptionally high. This observation can be confirmed by comparing the results with another project community. In project community 2 , the share of creators is higher $(40 \%)$ but the number of contributors is significantly lower $(8 \%)$. The number of lurkers is also higher than in project community 1 . The results for the different community types show, that the share of creators in project communities is substantially higher than in other communities. Consequently, the number of lurkers is lower. 
The analysis of teaching communities also reveals interesting results. Teaching communities are typically used to share teaching material with students. Thus, we expected to see a small share of contributors and a large share of lurkers. However, the results for the two teaching communities reveal distinctly different distributions of user types. Similarly, more than 70\% lurkers form the majority in these communities. However, the share of creators is unexpectedly high (around 20\%). On UniConnect, students are encouraged to engage with the lecturers by posting questions. Especially in the two teaching communities, students make use of the forum to start discussions on the course content and tasks.

Finally, we analyzed a community used to communicate information to all members of UniConnect. With more than $96 \%$, lurkers are the vast majority in this community. There are only very few contributors $(1.97 \%)$ and creators $(1.40 \%)$. This accurately reflects and confirms the purpose of this community. The platform owners use this community to share (broadcast) announcements and share information unidirectional $(1: n)$. Thus, the share of creators is very low and only few users provide information and announcements.

\section{Discussion, Limitations and Outlook}

In this paper, we propose a user typology for ECS (RQ 1). We address limitations in existing user typologies (e.g. "self-selected" user types [23] or fuzzy/overlapping dimensions [2]). This paper contributes to theory by proposing an ECS user typology based on five dimensions of ECS use (RQ 2) that can be used for Social Collaboration Analytics. We argue that the dimensions choice of content type and platform preferences should be addressed separately, as shown above and not be included in fixed definitions. The ECS user typology helps to gain an understanding of user behavior in collaboration. The typology is precise and can be used to phrase database queries that can help both platform owners and community managers to understand usage and collaboration on their platform thus also providing a contribution to practice (RQ 3).

The literature presents inconsistent figures to distinguish creators from contributors. We argue that the thresholds need to be adjusted depending on the context of the investigation. On the platform level, a higher value might be required than on the community level and the purpose for which the ECS is introduced should be considered as well.

The results of the analysis revealed several interesting findings. While the majority of users are indeed lurkers, the number of lurkers on UniConnect is not as high as often mentioned in the literature. Additionally, the analysis shows that contributing behavior of users should be analyzed on different levels. The distribution of user types for specific communities allows the drawing of conclusions on the purpose and health of a community. Communities with a larger number of contributors and creators indicate joint collaboration and thus are most likely project-related communities.

Whilst our typology is technology agnostic, our first application of the user typology was limited to IBM Connections. In future work, we will develop middleware that enables the application of the user typology to multiple heterogeneous collaboration systems. This would also allow investigation of the dimension "platform preference". Most organizations have a portfolio of different applications for collaboration. Thus, the dimension platform preference would help to identify the platforms that users prefer for participation and for consuming information.

\section{References}

[1] Bezzubtseva, A., and D.I. Ignatov, "A Typology of Collaboration Platform Users", Workshop on Experimental Economics in Machine Learning, (2012), 9-19.

[2] Blank, G., and D. Groselj, "Dimensions of Internet use: amount, variety, and types", Information, Communication \& Society 17(4), 2014, pp. 417-435.

[3] Brandtzæg, P.B., "Towards a unified Media-User Typology (MUT): A meta-analysis and review of the research literature on media-user typologies", Computers in Human Behavior 26(5), 2010, pp. 940-956.

[4] Brandtzaeg, P.B., and J. Heim, "A typology of social networking sites users", International Journal of Web Based Communities 7(1), 2011, pp. 28-51.

[5] Brunker, A.S., Q.V. Nguyen, A.J. Maeder, et al., "A time-based visualization for web user classification in social networks", Proceedings of the 7th International Symposium on Visual Information Communication and Interaction, ACM (2014), 98.

[6] Cranefield, J., P. Yoong, and S.L. Huff, "Rethinking lurking: Invisible leading and following in a knowledge transfer ecosystem", Journal of the Association for Information Systems 16(4), 2015, pp. 213-247.

[7] Egea, J.M.O., M.R. Menéndez, and M.V.R. González, "Diffusion and usage patterns of Internet services in the European Union”, InformationResearch 12(2), 2007.

[8] Eynon, R., and L.-E. Malmberg, "A typology of young people's Internet use: Implications for education", Computers \& Education 56(3), 2011, pp. 585-595.

[9] Farzan, R., J.M. DiMicco, and B. Brownholtz, "Mobilizing Lurkers with a Targeted Task", 4th International AAAI Conference on Weblogs and Social Media, (2010).

[10] Ganley, D., C. Moser, and P. Groenewegen, "Categorizing Behavior in Online Communities: A Look Into the World of Cake Bakers", 45th Hawaii International Conference on System Sciences, (2012), 3457-3466. 
[11] Glitsch, J.H., and P. Schubert, "IRESS: Identification of Requirements for Enterprise Social Software", Procedia Computer Science, Elsevier B.V. (2017), 866-873.

[12] Golder, S.A., and J. Donath, "Social roles in electronic communities", Internet Research 5(1), 2004, pp. 19-22.

[13] Han, J.Y., J. Hou, E. Kim, and D.H. Gustafson, "Lurking as an Active Participation Process: A Longitudinal Investigation of Engagement with an Online Cancer Support Group", Health Communication 29(9), 2014, pp. 911-923.

[14] Hausmann, V., and S.P. Williams, "Issues for the long-term management of Social Business Documents", International Journal of Information Systems and Project Management 4(3), 2016, pp. 45-61.

[15] Heim, J., and P.B. Brandtzæg, "Patterns of Media Usage and the Non-professional Users", (2007).

[16] Holmes, J., "Cyberkids or divided generations? Characterising young people's internet use in the UK with generic, continuum or typological models", New Media \& Society 13(7), 2011, pp. 1104-1122.

[17] Horrigan, J.B., A typology of information and communication technology users, Washington, DC, USA, 2007.

[18] Howard, P.E.N., L. Rainie, and S. Jones, "Days and nights on the Internet: The impact of a diffusing technology", American Behavioral Scientist 45(3), 2001, pp. 383-404.

[19] Kügler, M., S. Smolnik, and G. Kane, "What's in IT for employees? Understanding the relationship between use and performance in enterprise social software", Journal of Strategic Information Systems 24(2), 2015, pp. 90-112.

[20] Lee, J., I. Kim, and H. Lee, "Generalizing ICT User typologies", Pacific Asia Conference on Information Systems, (2016), 375.

[21] Livingstone, S., and E. Helsper, "Gradations in digital inclusion: children, young people and the digital divide", New Media \& Society 9(4), 2007, pp. 671-696.

[22] Muller, M., "Lurking as personal trait or situational disposition: lurking and contributing in enterprise social media", Conference on Computer Supported Cooperative Work, (2012), 253-256.

[23] Muller, M., N.S. Shami, D.R. Millen, and J. Feinberg, "We are all lurkers: consuming behaviors among authors and readers in an enterprise file-sharing service", 16th ACM international conference on Supporting group work, (2010), 201-210.

[24] Nonnecke, B., and J. Preece, "Shedding light on lurkers in online communities", Ethnographic Studies in Real and Virtual Environments: Inhabited Information Spaces and Connected Communities, Edinburgh, 1999, pp. 123-128.

[25] Nonnecke, B., and J. Preece, "Lurker demographics: Counting the silent", Proceedings of the SIGCHI conference on Human Factors in Computing Systems, ACM (2000), 7380.

[26] van Osch, W., and C. Steinfield, "Boundary Spanning through Enterprise Social Software: An External Stakeholder Perspective", 34th International Conference on Information Systems, (2013).

[27] Rafaeli, S., G. Ravid, and V. Soroka, "De-lurking in virtual communities: a social communication network approach to measuring the effects of social and cultural capital", 37th Annual Hawaii International Conference on System Sciences, 2004. Proceedings of the, (2004), 10 pp.-.

[28] Richter, A., S. Behrendt, and M. Koch, APERTO: A Framework for Selection, Introduction, and Optimization of Corporate Social Software, 2012.

[29] Ridings, C., D. Gefen, and B. Arinze, "Psychological barriers: Lurker and poster motivation and behavior in online communities", Communications of the Association for Information Systems 18(1), 2006, pp. 16.

[30] Riemer, K., J. Finke, and D. Hovorka, "Bridging or Bonding: Do Individuals gain Social Capital from Participation in Enterprise Social Networks?", 36th International Conference on Information Systems (ICIS), (2015).

[31] Schubert, P., and J.H. Glitsch, "Use Cases and Collaboration Scenarios: How employees use sociallyenabled Enterprise Collaboration Systems (ECS)", International Journal of Information Systems and Project Management 4(2), 2016, pp. 41-62.

[32] Schwade, F., and P. Schubert, "Social Collaboration Analytics for Enterprise Collaboration Systems: Providing Business Intelligence on Collaboration Activities", 50th Hawaii International Conference on System Sciences (HICSS), (2017), 401-411.

[33] Schwade, F., and P. Schubert, "A survey on the status quo of Social Collaboration Analytics in practice", 25th European Conference on Information Systems (ECIS), (2018).

[34] Schwade, F., and P. Schubert, "Social Collaboration Analytics for Enterprise Social Software: A Literature Review", Multikonferenz Wirtschaftsinformatik 2018, (2018).

[35] Selwyn, N., S. Gorard, and J. Furlong, "Whose Internet is it anyway? Exploring adults'(non) use of the Internet in everyday life", European Journal of Communication 20(1), 2005, pp. 5-26.

[36] Sun, N., P.P.-L. Rau, and L. Ma, "Understanding lurkers in online communities: A literature review", Computers in Human Behavior 38, 2014, pp. 110-117.

[37] Vaishnavi, V., and B. Kuechler, "Design Science Research in Information Systems Overview of Design Science Research", Design Science Research in Information Systems and Technology, 2004.

[38] Viol, J., R. Bernsmann, and K. Riemer, "Behavioural Dimensions for Discovering Knowledge Actor Roles Utilising Enterprise Social Network Metrics", Australasian Conference on Information Systems, (2015), 113.

[39] Williams, S.P., Enterprise 2.0 and collaborative technologies, University of Koblenz-Landau, Koblenz, Germany, 2010.

[40] Williams, S.P., V. Hausmann, C.A. Hardy, and P. Schubert, "Enterprise 2.0 Research: Meeting the Challenges of Practice", 26th International Bled eConference, (2013), 251-263.

[41] Williams, S.P., and P. Schubert, "Connecting Industry: Building and Sustaining a Practice-based Research Community", 50th Hawaii International Conference on System Sciences (HICSS), (2017), 5400-5409. 